\title{
Active Dust Mitigation Technology for Thermal Radiators Por Lunar Exploration
}

\author{
C.I. Calle', C.R. Buhler, M.D. Hogue', M.R. Johansen', V.B. Cruz ${ }^{3}$, J.W. Hopkins, ${ }^{3}$ N.M.H. \\ Holloway, ${ }^{3}$ J.W. Connell, ${ }^{3}$ A. Chen ${ }^{4}$, S.A. Irwin ${ }^{5}$, S.O. Case ${ }^{6}$, N.J. Van Suetendael ${ }^{1}$, S.J. \\ Snyder ${ }^{2}$, and J.S. Clements ${ }^{7}$ \\ ${ }^{1}$ Electrostatics and Surface Physics Laboratory, NASA, Kennedy Space Center, FL 32899; Ph \\ 321-867-3274; email: carlosi.calle@nasa.gov \\ ${ }^{2}$ ASRC Aerospace, Kennedy Space Center, FL 32899 \\ ${ }^{3}$ NASA Langley Research Center, Hampton, VA 23681 \\ ${ }^{4}$ Department of Physics, Oklahoma Baptist University, Shawnee, OK 74804 \\ ${ }^{5}$ Department of Physics and Space Sciences, Florida Institute of Technology, Melbourne, FL \\ 32901 \\ ${ }^{6}$ Department of Physics, Virginia Polytechnic Institute and State University, Blacksburg, VA \\ 24061 \\ ${ }^{7}$ Department of Physics and Astronomy, Appalachian State University, Boone, NC 28608
}

\begin{abstract}
Dust accumulation on thermal radiator surfaces planned for lunar exploration will significantly reduce their efficiency. Evidence from the Apollo missions shows that an insulating layer of dust accumulated on radiator surfaces could not be removed and caused serious thermal control problems. Temperatures measured at different locations in the magnetometer on Apollo 12 were $38^{\circ} \mathrm{C}$ warmer than expected due to lunar dust accumulation.

In this paper, we report on the application of the Electrodynamic Dust Shield (EDS) technology being developed in our NASA laboratory and applied to thermal radiator surfaces. The EDS uses electrostatic and dielectrophoretic forces generated by a grid of electrodes running a $2 \mu \mathrm{A}$ electric current to remove dust particles from surfaces. Working prototypes of EDS systems on solar panels and on thermal radiators have been successfully developed and tested at vacuum with clearing efficiencies above $92 \%$. For this work, EDS prototypes on flexible and rigid thermal radiators were developed and tested at vacuum.
\end{abstract}

\section{INTRODUCTION}

The thermal conductivity of the lunar regolith is temperature dependent. The efficiency of the radiative transfer process between the fine powdery particles of the surficial regolith is proportional to the cube of the absolute temperature. Thus, heat fows more readily into the surroundings during daylight than at night. Overall, the thermal conductivity of the regolith strongly inhibited the flow of energy (Harland 1999). The powdery regolith is such an efficient thermal insulator that, at a depth of 0.5 meters, the temperature remains at a constant $240 \mathrm{~K}$, unaffected by the dimal temperature variation from $100 \mathrm{~K}$ to $380 \mathrm{~K}$ (at the midnorthem latitude where the Apollo 17 Heat Flow Experiment took place). The granular regolith also prevents heat from the interior of the moon from leaking out, building up below the surface. 
The thermal insulating properties of the lunar dust is expected to degrade thermal radiation systems when dust is transported to these systems as a result of lunar exploration activities that can disturb the powdery top layer of the regolith (Gaier 2005. A method to actively remove dust from the surfaces of thermal radiation systems is required to maintain the proper efficiencies of thermal radiators. The Electrodynamic Dust Shield (EDS), currently being developed in our laboratory (Biris 2004, Calle 2004, 2005, 2006, 2007, 2009), is being successfully implemented to thermal radiators.

Two main types of thermal radiators are being considered for lunar exploration. The first is to coat the surface with a radiative paint. The most common paint is AZ-93 Thermal Paint, AZ-93 is an inorganic white thermal control paint developed for use on spacecraft / satellite surfaces exposed to the deleterious effects of the space environment. Application of AZ -93 creates a white coating that allows only $14-16 \%$ of the solar radiation impinging on the spacecraft external surface to be absorbed through to the interior systems while emitting 89 $93 \%$ of the internal heat generated to the cold vacuum of space. AZ-93 has been thoroughly tested and is currently being used on external surfaces of the International Space Station.

The second method to protect objects from incident radiation is the use of flexible, reflective materials. Fluoro Ethylene Polypropylene (FEP) is a transparent polymer material which is high flexible and is robust against oxygen attack and serves as the mechanical support for a vapor-deposited layer of highly reflective metal. Two metals that are commercially available that are vapor deposited onto the FEP are aluminum and silver. $\mathrm{Ag} / \mathrm{FEP}$ has slightly better thermal characteristics but is more expensive. Since silver is prone to oxygen attach, an inconel layer is deposited on top of the Ag giving the material a greenish tinge. This method is used were painting a spacecraft surface is not feasible. Users simply remove a certain amount of $\mathrm{A} / \mathrm{Ag}$ coated $\mathrm{FEP}$ from large rolls to cover a section of spaceflight hardware that needs thermal protection.

\section{ELECTRODYNAMIC DUST SHIELD DESIGN}

The use of the Electrodynamic Dust Shield on insulating surfaces has been demonstrated repeatedly as in the case of transparent surfaces such as windows or solar panels. However, the application of this technology has not been demonstrated on well-grounded metallic substrates such as those surfaces requiring thermal radiators. Thermal paint for example, is typically applied to the exposed metal skin of a spacecraft while FEP radiator materials are cut from a roll and used to wrap parts and pieces that require protection. In both cases, transparency is not required but close exposure to grounded metal planes or objects is almost a certainty. The original design of the Electrodynamic Shield did not account for grounded metal planes nearby which could lead to unwanted electrical breakdown depending upon the geometry of the configuration. However, knowing that a grounded metal plane exists nearby it is possible to alter the electric field configurations to account for it. This is exactly what was done. The only real requirements for moving dust off a specific area that needed cleaning on the Electrodynamic Shield were to have highly divergent, (in space and time) strong electric fields in the presence of the particles.

Thermal Paint. Developing an active dust mitigation technique for removing dust on surfaces covered with AZ-93 thermal paint involves several steps. The first step is to cover the aluminum substrate (or any metallic substrate in need of themal protection) with a strong dielectric material to allow the application of large voltages and large electric fields at the 
particle's location. One of the best known dielectrics with excellent breakdown strength properties is polyimide. Polyimide typically has breakdown strengths which exceed 3.3 $\mathrm{kV} / \mathrm{mil}$. For this project we used three forms of polyimide as our dielectric barrier. The first is the well-known polyimide commercially avallable by DuPont known as Kapton ${ }^{3}$. The second is a formulation created by the NASA Langley Research Center known as LaRC-SI, a liquid formulation of polyimide. The third was another polyimide created by the Applied Chemistry Laboratory at the NASA Kennedy Space Center which was a liquid formulation variation of the commercially available Upilex ${ }^{\text {B }}$.

Once the dielectric barrier was applied, the next step is to create the electrode pattern. This can be done using several methods. Sheldahl (Northfield, MN) who supplies Ag/FEP and Al/FEP also provide copper-coated Kapton which can be etched to form a grid pattern. Most of Sheldah's metal covered polymer sheets have metal thicknesses of approximately $1000 \AA$ that was created using physical vapor deposition. Thus choosing to use a commercially available metal coated polymer sheet eliminates the need to sputter coat metal onto plain polyimide. Sputter coating the metal of choice is warranted in this case since typically $1000 \AA$ of metal does not provide enough sustainable current density to run the Electrodynamic Shields.

The hydrophillic nature of $\mathrm{AZ}-93$ thermal paint means that the paint is not electrically insulating at room conditions. Water absorption within the paint itself lowers the surface resistance from $\sim 10^{12} \Omega$ at high vacuum down to $\sim 10^{6} \Omega$ at room conditions which is a six orders of magnitude change. Thus it is vital to have a dielectric overcoat on top of the electrode pattern to prevent sparking. This top dielectric layer also serves to protect workers and personnel from electrical shock during Shield operation. This top dielectric layer can also be one of the three polyimide formations mentioned above.

Once the electrical section of the thermal radiators is complete, the AZ-93 thermal paint can be applied. In order to allow the thermal paint to adhere to the polyimide surface, AZ Technology recommends the use of MLP-300 AZ primer first. The twompart primer is applied and allowed to dry before the application of AZ-93. A complete schematic of the finished product is shown below in Figure 1 .

\begin{tabular}{|c|}
\hline AZ-93 Thermal Paint (5 mils) \\
\hline Grounded Metallic Spacecraft: \\
\hline
\end{tabular}

Figure 1. Schematie of the cross-section of a surface with the Electrodynamic Dust Shield embedded into substrate coated with AZ-93 thermal paint.

Siver and Alumimum Coated ER. The flexible radiator materials must also produce large divergent electric fields at the surface. However, the constraints are more stringent when it comes to the metal-coated FEP materials since the sunlight must traverse the polymer. Thus one camnot use of Kapton ${ }^{3}$ for optical reasons. There is however, a transparent form of Kapton ${ }^{2}$ called CP-2 (Clear Polyimide-2 by ManTech) which could be used but at this time it is cost prohibitive.

Fortunately the FEP itself is an excellent dielectric with excellent breakdown properties. The standard commercially available 5 mil thick FEP is strong enough to withstand 10,000 volts when tested using ASTM-D149 (ASTM 2004). This allows the FEP 
itself to act as the dielectric. Once this determination is made, it is simple manner to transform a commercially available radiator material into a self-cleaning dust mitigator.

There are a couple of methods available to make FEP radiators. The first involves applying a thick layer of metal to the surface of the FEP though physical vapor deposition via sputter coating or evaporation. Once the layer is deposited the metal must be etched to form the grid. The highest success we have had was to use laser ablation form the pattern (performed at NASA LaRC). Once the grid is on the FEP, the backside of the material requires a solid layer of metal. This layer serves as the electrical ground and at this point the radiator could be said to be complete. Although there is no protective outer layer, dust will still be removed from the surface upon the application of high voltage to the grid plane. Furthermore, the high dielectric breakdown strength of the vacuum should prevent sparking. In the case that this is not acceptable an additional thin layer of about 1-2 mils of FEP could be applied to the top layer using an autoclave.

The disadvantage of this approach is that the grid layer may not be as reflective as the ground layer. The smoothness of the FEP is what gives the deposited metal its reflective properties. Otherwise the amorphous nature of the deposition process makes the aluminum and silver grid appear cloudy on the backside. Since thermal performance measurements have yet to have been made on these systems, it is difficult to guess whether the performance is degraded by this approach.

A second method to make the FEP radiators is by simply sandwiching two Al or Ag coated FEP materials together. The radiator is formed by applying a gridded FEP against a non-gridded FEP sample. The aluminum or silver side of the gridded sample is up against the FEP side of the grounded sample. The materials are heat pressed together at about $500^{\circ} \mathrm{F}$ in an autoclave. If the transparency of the FEP is not compromised, this radiator would be a highly desirable design that does not suffer from optical degradation caused by appearance of the backside of the vapor deposited metal layer and it also contains a built-in top layer for dielectric protection. Ideally one would prefer this topmost layer to be as thin as possible to allow the maximum number of electric field lines to protrude the surface; however this can be compensated with by simply raising the voltage on the electrodes. Figure 2 is a schematic representation of the FEP radiators.

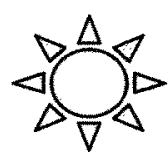

Laser Ablated HV grid

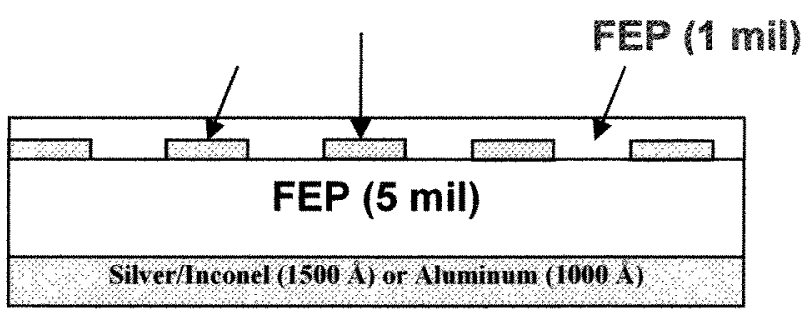

Active Dust Shield Thermal

Radiator (no protective layer)

Figure 2. Schematic of the Active Dust Shield WEP Thermal Radiators. 


\section{THERMAL PANT TESTS}

Several test coupons were built to test a variety of combinations to use with the thermal paint. Most were placed on either $3^{\prime \prime} \times 5^{\prime \prime}$ aluminum coupons (Q-panel Corp.) listed above or 1" aluminum disks to prepare for tests in a specialized vacuum chamber. The large coupons were easier to work with while the use of small coupons was required since those are the size that fit into the chamber.

There were several dielectric coatings/electrode combinations applied to the test coupons. The dielectric coatings consist of 2 or 3 coats of LaRC-SI polyimide, the NASA KSC Applied Chemistry Laboratory polyimide or commercial 5 mil Kapton adhered using $3 M^{\mathrm{TM}}$ Adhesive Transfer Tape.

The grid material used was copper or aluminum targets that were sputtered on using either an in-house sputter coater or provided by the vendor. LaRC used an evaporator to deposit metals on their LaRC-SI coatings. To make the grid patterns, samples made at KSC were either masked during sputtering or pattemed and chemically etched. LaRC used a photolithography process to provide a positive mask on their samples prior to chemical etching. The grid patterns were typically $2 \mathrm{~mm}$ spacing or $4 \mathrm{~mm}$ spacing. The trace width was nominally $300 \mu \mathrm{m}(0.3 \mathrm{~mm})$.

The choice of the top layer varied considerably since according to the manufacturer, the AZ-93 paint should adhere to metallic surfaces and possess very well insulating electrical properties. To satisfy this requirement, several radiators were fabricated using the metal electrode grid in direct contact with the AZ-93 thermal paint. Although copper is usually chosen for its high conductivity properties, it is well known that AZ-93 adheres to aluminum, thus some sample grids were made of aluminum instead to improve adherence. Finally, a few samples were coated with a dielectric just in case sparking was to occur. Samples were coated with either another coat of LaRC.SI, ACL polyimide or commercial Upilex ${ }^{\text {. The average }}$ thickness of the radiator prior to painting was 1.79 mils for the LaRC-SI coated $3^{\prime \prime} \times 5^{\prime \prime}$ coupons, 2.32 mils for the ACL polyimide coated $3^{\prime \prime} \times 5^{\prime \prime}$ coupons, and 2.23 mils for all of the

1 " diameter round coupons. The largest thickness was for the three Upilex samples which were 9.39 mils due to the $5 \mathrm{mil}$ commercial film used. Ideally one would want the dielectriclelectrode/dielectric thickness to be minimal for maximum themal protection. It is unknown at this time how the thickness of the different layers affects the themal properties of the materials.

Attaching wires to the electrodes is a non-trivial process. Any exposed electrode leads to electrical breakdown and to destruction of the radiator. One successful method was to attach a WV wire to the exposed copper-coated (or aluminum-coated) radiator grid using silver paint topped with 5-minute epoxy. Once the radiators were complete they were ready to be painted and tested in air and high vacum conditions using 50-100 um sized JSC-1A lunar simulant.

\section{RESULTS}

It was realized very early in the testing of the AZ-93 thermal paint radiators that the paint was not insulating at room conditions but statically dissipative, meaning that the paint possessed surface resistances less than $10^{9} \Omega$. Thus the paint shorted out the electrodes upon the application of voltage and further testing in room air was not performed. However, the 
placement of the AZ-93 thermal painted samples inside either the dry box with relative humidity less than $1 \%$ or in high vacuum $\left(10^{-6}\right.$ torr) removed moisture from the samples.

Preliminary dust removal tests were performed on the AZ-93 painted coupons. About $50 \mathrm{mg}$ of 50-100 $\mu \mathrm{m}$ sized JSC-1A dust was placed on top each sample while inside a vacuum chamber. A large $2^{\prime} \times 3^{\prime}$ vacuum chamber was pumped down to about $5 \times 10^{-7} \mathrm{kPa}$ using a $12^{\prime \prime}$ turbo molecular pump. The high voltage electrode of each radiator was connected through a feedthrough to a high voltage amplifier (Trek Model 10/10B) with input provided by a function generator and monitored using an oscilloscope (Sony Tektronics TDS 3052B). The standard testing procedure consisted of running the radiators at $1 \mathrm{kV}$ using a square waveform at $10 \mathrm{~Hz}$. The voltage would be stepped up by 500 volt increments and the resulting dust motion would be noted by visual means through a quartz viewport. Figure 3 shows a painted dust shield after dust removal at $2 \mathrm{kV}$.

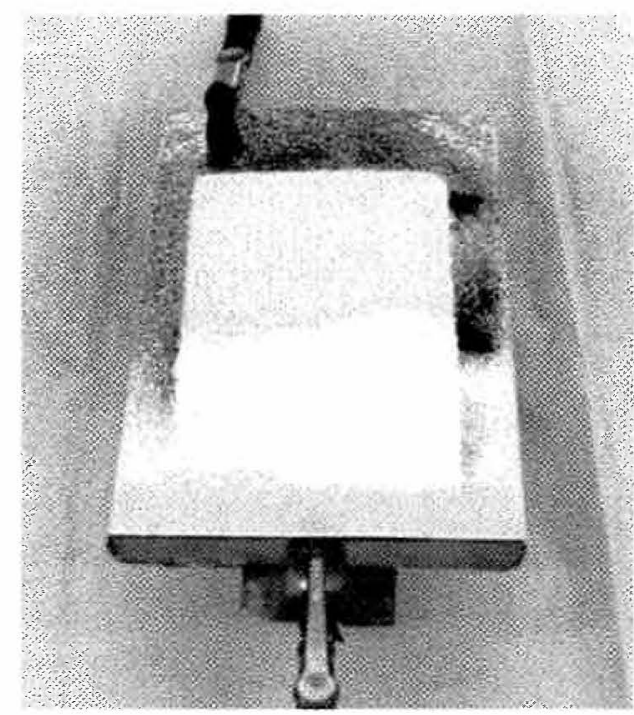

Figure 3. Electrodymamic Dust Shield on Kapton substrate painted with AZ-93 paint after dust shield activation at $5 \times 10^{-7} \mathrm{kPa}$.

The electrodes on the initial painted dust shields were built on a layer of Kapton ${ }^{\circledR} 2$ mils thick. The narrow thickness of this layer prevented the application of $\mathrm{AC}$ signals stronger than $2 \mathrm{kV}$, thus limiting the dust removal efficiency. Current designs now in production with Kapton ${ }^{2}$ coatings 10 to 20 mils thick have withstood larger potentials and shown performances nearing $99 \%$. We will report on those results in the near future.

\section{CONCLUSIONS}

The Electrodynamic Dust Shield is being developed to protect themal radiator surfaces to be used in manned lunar exploration activities. Dust shields were constructed for two main types of themal radiators. Both types involved the implementation of the dust shield on a metallic surface, a design that had not been required for earlier versions of the dust shield. For the first kind, dust shield electrodes were placed under the AZ-93 themal coating that will provide the themal control for solid metallic surfaces. For the second type, dust shield electrodes were 
also built into flexible, reflective silver and aluminum coated fuoroethylene polypropylene films that will protect equipment and systems on the moon.

Thermal radiator coupons containing dust shields were tested and optimized at $10^{-6}$ $\mathrm{kPa}$ with dry JSC-1A lunar stimulant in the under 50-100 micrometer fraction. Preliminary tests showed encouraging dust removal results, as illustrated in figure 3 . These initial tests were done with painted coupons containing a layer of Kapton that had a thickness of 2 mils and thus limited the potentials to be under $2 \mathrm{kV}$. Removal efficiencies are expected for larger potentials, and new designs are currently under development that will allow for these signals. Limited testing of these new designs have shown removal efficiencies that approach $99 \%$.

\section{ACKNOWLEDGEMENTS}

This project is funded by NASA's Exploration Development Program. The authors wish to thank Nancy Zeitlin and Michelle Amos of NASA Kennedy Space Center for their support.

\section{REWCRENCES}

Biris, A.S., R.A. Sims, J.D. Wilson, M.K. Mazumder, C.I. Calle, C.R. Buhler, "Transparent Self-Cleaning Shield for Solar Panels," IEEE Industrial Applications Transactions, (2004)

Calle, C.I., C.R. Buhler, J.G. Mantovani, S. Clements, A. Chen, M.K. Mazumder, A.S. Biris, and A.W. Nowicki, "Electrodynamic Dust Shield for Solar Panels on Mars, Lunar and Planetary Science XXXV, 2014 (2004)

Calle, C.I., "Dust Shield Technology for Lunar and Mars Exploration Activities," Space Operations Communicator" (2004)

Calle, C.I., C.R. Buhler, J.G. Mantovani, S. Clements, A. Chen, M.K. Mazumder, A.S. Biris, A.W. Nowicki, "Electrodynamic dust shield for solar panels on Mars," Workshop on Granular Materials in Lunar and Martian Exploration, Kennedy Space, Center, FL. (2005)

Calle, C.I., A. Chen, J. Meyer, B. Linell, C.R. Buhler, S. Clements, and M.K. Mazumder, "Numerical modeling of an electrostatic dust shield for the Martian and lunar environments," Earth and Space 2006, Houston (2006)

Calle, C.I., C. Immer, J.S. Clements, C. Buhler, A. Chen, J. Mantovan, P. Lundeen, and M. Michalenko, "Electrodynamic dust shield for surface exploration activities on the moon and Mars," Proceedings of the International Astronautical Congress, Valencia, Spain (2006)

Calle, C.I., J.G. Mantovani, C.R. Buhler, A. Chen, J.S. Clements, S. Trigwell, E.E. Arens, JM. McFall, and M.L. Riz, "Dust Mitigation Technologies for Lunar Exploration," Proceedings of the Intemational Conference on Explonation and Utization of the Moon, Sorrento, laly (2007)

Calle, C.I., M.K. Mazumder, C.D. Immer, C.R. Buhler, I.S. Clements, P. Lundeen, A. Chen, and J.G. Mantovani, "Controlled particle removal from surfaces by electrodynamic methods for terrestrial, lunar, and Martian environmental conditions," Proceedings of Electostatics 2007 . University of Oxford, UK, March $25-29,2007$ 
Calle, C.I., J.S. Clements, C.R. Buhler, J.G. Mantovani, A. Chen, E.E. Arens, J.M. McFall, and M.L. Ritz, "Mitigation of Lunar Dust in Mechanical Systems," Proceedings of the Space Technologies and Applications International Forum, Albuquerque (2008).

Clark, P.E., C.I. Calle, S.A. Curtis, J.F. Keller, F. Minetto, and J.G. Mantovani, "Electrostatic dust control on planetary surfaces," Proceedings of the Space Technologies and Utilization Forum, Albuquerque (2007)

Calle, C.I., E.E. Arens, J.M. McFall, C.R. Buhler, S.J. Snyder, J.K. Geiger, R.A. Hafley, and K.M. Taminger, Reduced gravity flight demonstration of the dust shield technology for optical systems, IEEE Aerospace Conference, \#1510 (2009)

Calle, C.I., C.R. Buhler, J.L. McFall, and S.J. Snyder, Particle removal by electrostatic and dielectrophoretic forces for dust control during lunar exploration missions. Journal of Electrostatics; $2009.67:$ p. $89-92$

Gaier, J.R., The Effects of Lunar Dust on EVA Systems During the Apollo Missions. NASA TM-2005-213610, 2005.

Harland, D.M. Exploration of the Moon-The Apollo Expeditions (Heidelberg:Springer: 1999)

Masuda, S., et al., Confinement and Transportation of Charged Aerosol Clouds via Electric Curtain. IEE Japan, $1972.92 \mathrm{~B}:$ p. 9-18

Mazumder, M., M. Zahn, R. Sharma, J. Zhang, C.I. Calle, C. Immer, and N. Mardesich, "Development of self-cleaning dust shields using low-power electrodynamic fields for solar panels on Mars," Proceedings of the 2006 ESA/IEJ/IEEE-LAS/SFE Joint Conference on Electrostatics, Laplacian Press, Morgan Hill, CA (2006)

ASTM, Standard Test Method for Dielectric Breakdown Volvage and Dielectric Strength of Solid Electrical Insulating Materials at Commercial Power Frequenciesl. ASTM D149- $97 \mathrm{a}, 2004$ 